\title{
Application of Structural Equation Modeling in Assessing the Relationship Between Stuttering Students' Cognitive and Metacognitive Strategies and Their Reading Comprehension Performance
}

\author{
HAMED GHAEMI \\ Department of English, Gonabad Branch, Islamic Azad University (IAU), Gonabad, \\ Iran
}

HAMIDE GHAEMI

Department of Speech and Language Pathology, Mashhad University of Medical Science, Mashhad, Iran

\section{Bio Data:}

Hamed Ghaemi is a PhD candidate in TEFL at University of Tehran, International Campus, Iran. He is a TEFL instructor at Islamic Azad University. His areas of research interests are Language Testing, E-assessment, ESP and Teacher Development. He has published several articles in international refereed journals and is currently the Head of IELTS department at the Jahan Elm Higher Education Institute, Mashhad, Iran. Email: hamedghaemi@ymail.com

Hamide Ghaemi recently graduated from Master Program in Speech and Language Pathology from Tehran University of Medical Science. She is currently an instructor at Mashhad University of Medical Science, Iran and has published several articles in national and international refereed journals. Email: hamideghaemi@yahoo.com

\begin{abstract}
Language testing is not limited to assessing the performance of ordinary learners. It is also needed in other field such as assessing the ability of children with disabilities, those who have language disorders. Although a great deal of research has been carried out in the realm of stuttering, researchers still do not know why some children stutter, or why most children become fluent speakers while others become adult stutterers. Studies show that Stuttering students have many difficulties in Reading Comprehension (Roberts \& Erdos, 1993). It is stated in the Reading Comprehension literature that cognitive and
\end{abstract}


metacognitive strategies have a crucial role in reading comprehension performance. The present study aims at investigating the relationship between cognitive and metacognitive strategies of stuttering students through using Structural Equation Modeling (SEM). The findings of the study show that there is a meaningful relationship between Cognitive and Metacognitive strategies of stuttering students. However, there is no statistically significant relationship between the Cognitive strategies and Reading Comprehension of Stuttering Students.

Keywords: Cognitive strategies, Metacognitive strategies, Structural Equation Modeling (SEM), Stuttering Students

\section{Introduction}

Stuttering is an age old difficulty. As long as people have been talking, some have been bothering with this disorder. There are more than fifteen million people who stutter in the world nowadays, and the majority is children.

Children who stutter show puzzling problems to their parents and teachers. Parents wonder what can be the reason of the breaks in fluency. They wonder too, why the difficulty differs so much. On some days, and sometimes for weeks, little or no trouble is noticeable, then, unexpectedly, the speech of some teenagers is filled with long series of repetitive words or syllables, obvious facial contortions or even more abnormal evidences of injure and attempt. Although a great deal of research has been done in the area of stuttering, researchers still do not know why some children stutter, or why most children become fluent speakers while others become adult stutterers. The surroundings play a very significant role in determining how students who stutter feel about themselves, and how their speech will be affected by definite situations. Most of the studies completed formerly have 
used overt speech production. This may or may not have included stuttered speech in the people who stutter. Using overt speech production creates some difficulties for data acquisition but, more outstandingly, it is not feasible to tell if the abnormal patterns of speech production are a reason or a result of stuttered speech. Researchers used functional MRI to scan the brains of people who stutter and fluent speaking control participants during three conditions: (i) while they listened to sentences; (ii) while reading sentences silently; (iii) while reading sentences and listening to the same sentence being read by someone else. They wanted to know if the same patterns of abnormal brain activity would be seen in people who stutter even when they are not producing speech.

They found atypical patterns of activation in people who stutter in acoustic and motor brain areas but these patterns were different to those seen previously and during speech production. In contrast with earlier findings, the auditory areas of the brain that reacted to listening to other people speaking depicted more activity in the people who stutter than the controls; when listening to self-produced speech this region normally had less activity in stutterers than in controls.

Similarly, some studies shown that stuttering students have many problems in reading comprehension (See Phakiti, 2003, Purpura, 1996, Sasaki, 1993). Several causes were mentioned as the reasons of this problem and among them the role of cognitive and metacognitive was very significant. Current definitions admit that reading comprehension includes the 
construction of meaning from text using an extensive range of skills and knowledge (e.g., National Reading Panel, 2002; Snow, Burns, \& Griffin, 1998). The National Assessment of Educational Progress (NAEP) 2009 Reading Framework Committee defines reading comprehension as ..."an active and complex process that involves appreciating written text, developing and interpreting meaning, and using meaning as appropriate to type of text, purpose and situation" (National Center for Educational Statistics, 2005, p. 2).

To build meaning, readers must decode words easily, comprehend vocabulary, make inferences, and link the ideas in text to their previous knowledge and experiences. These skills differ with age, experience, instruction, context, and motivation so both the processes and the products of reading comprehension are constructive, multidimensional, developmental, and changeable. Therefore, reading comprehension is complicated to describe plainly and measure carefully. However, the present study also aims at investigating the relationship between cognitive and metacognitive strategies and reading comprehension of stuttering students.

\section{An overview of cognition and metacognition}

\section{Cognition}

The word cognition is taken from the Latin word cognitio, meaning "to get to know, to learn." Understanding how human beings think and learn is a methodical, philosophical and behavioral dispute, because the process of learning involves biological properties, physiological activities, feelings, behaviors, thoughts and memories. 
A human being's biological "thought system" processes information, which results in learning. The brain interprets input, stores it for future use and applies it to new situations. A lot of elements go into the "brain blender" and are blended with what is already in there. New input is added to the presented inventory of information, compared with what is already identified, and organized with, or connected to, related information so that this new understanding can be referenced in the future. The brain ought to be in the accurate cognitive phase in order to learn. There are exact phases that people move through as they build upon existing knowledge.

Although the child may parrot back the word, after hearing his parent say it again and again as holding up the corresponding flash card, the little one is in fact distinguishing a figure of the word on the card. Organizing things into series and patterns is indeed an age fitting learning product for a young child. So much of one's capability to learn is based upon noticing patterns, sequencing objects, comparing differences and similarities.

People learn through different ways. Some adults prefer to systematically read the directions former to putting something together, while others only look over the diagrams and still others jump right in and do it on the fly, relying on their ability to organize, manipulate and fit objects together. At different periods in their development, students need different learning modalities. For instance, middle schoolers learn efficiently by "doing" - e.g., playing math games and acting out historical scenes. 
Truthfully, Human Cognition is an enormous and complex issue. Regardless of complicated medical imaging procedures and intuitive psychoanalysis, researchers in reality cannot "get inside someone's head" to work out what is going on. Researchers can only collect data and attempt to develop their own explanations of the data. However, continued observation, research and scientific experiments will add to scientists' understanding of understanding. They will continue to learn how humans learn and in the process discover progressively more effective procedures and trends to language, memory, the senses and human behavior.

\section{Metacognition}

Metacognition" is one of the most recent expressions in educational psychology. The extent and conceptual nature of the word makes it sound daunting, however it's not as frightening a concept as it might appear. Metacognition enables human to be triumphant learners, and has been associated with intelligence (e.g., Borkowski, Carr, \& Pressley, 1987; Sternberg, 1984, 1986a, 1986b). Metacognition refers to higher order thinking which includes active control over the cognitive processes involves in learning. Activities such as planning how to approach a given learning task, examining comprehension, and assessing development toward the completion of a task are metacognitive in nature.

"Metacognition" is often basically defined as "thinking about thinking." In reality, defining metacognition is not that simple. Even though the term has been part of the vocabulary of educational psychologists for the last decades 
there is much discuss over precisely what metacognition is. One reason for this mystification is the fact that there are several terms presently used to describe the same basic evidence or a facet of that phenomenon, and these terms are often used interchangeably in the literature. While there are some differences between definitions (Van Zile-Tamsen, 1994, 1996), all stress the role of supervisory processes in the overseeing and regulation of cognitive processes.

The word "metacognition" is most often related with John Flavell, (1979). According to Flavell (1979, 1987), metacognition embraces both metacognitive knowledge and metacognitive experiences. Metacognitive knowledge refers to acquired knowledge about cognitive processes, knowledge that can be utilized to control cognitive processes.

Because metacognition plays a vital role in successful learning, it is significant to study metacognitive activity and development to find out how students can be educated to better use their cognitive resources through metacognitive control.

\section{Cognitive vs. Metacognitive Strategies}

Most of the definitions given for metacognition include both knowledge and strategy components; still, there are a number of problems linked with using such definitions. One main problem involves sorting out what is cognitive from what is metacognitive. What is the difference between a cognitive and a metacognitive strategy? 
Flavell himself admits that metacognitive knowledge may not be different from cognitive knowledge (Flavell, 1979). The difference lies in how the information is used.

As said earlier metacognition is referred to as "thinking about thinking" and involves control whether a cognitive aim has been met. This should be the crucial criterion for determining what is metacognitive. Cognitive strategies are used to assist a person attain a particular goal while metacognitive strategies are employed to guarantee that the goal has been reached. Metacognitive experiences often happen when cognitions stop working, such as the recognition that one did not understand what one just read. Such a stalemate is believed to trigger metacognitive processes as the learner attempts to repair the condition (Roberts \& Erdos, 1993).

Metacognitive and cognitive strategies may overlap in that the same strategy could be considered as either a cognitive or a metacognitive strategy depending on what the rationale for using that strategy is. For instance, one might use a self-questioning strategy while reading as a means of obtaining knowledge (cognitive), or as a way of checking what one has just read (metacognitive). Since cognitive and metacognitive strategies are closely entwined and dependent upon each other, any effort to scrutinize one without acknowledging the other would not offer an ample picture.

\section{Background to structural equation modeling}

Structural Equation Modeling is a very powerful multivariate analysis method that includes particular versions of a number of other analysis techniques as 
special cases. The old definition of SEM was expressed by the geneticist Sewall Wright (1921), and officially defined by Judea Pearl (2000) using counterfactuals. The structural equation modeling (SEM) process focuses around two phases: validating the measurement model and fitting the structural model. The former is done mainly through confirmatory factor analysis, while the latter is carried out principally through path analysis with latent variables.

Structural equation models can do both confirmatory and exploratory modeling, meaning that they are suitable for both theory testing and theory development. Confirmatory modeling mostly begins with a hypothesis that is usually presented in a causal model. The model is tested against the obtained data to determine how well the model fits the data (Bollen, and Long, 1993).

SEM can be used by identifying an analogous model and using data to estimate the values of free parameters. Frequently, the original hypothesis needs adjustment in light of model confirmation. Wright (1921) stated that when SEM is used purely for exploration, this is usually in the framework of exploratory factor analysis as in psychometric design (Wright, 1921).

Bollen, and Long (1993) pointed out that among the strengths of SEM is the ability to construct latent variables: variables which are not measured directly, but are estimated in the model from several measured variables each of which is predicted to 'tap into' the latent variables (Bollen, and Long, 1993). The qualitative causal assumptions are represented by the missing variables in each equation, and fading covariance among some error terms. These 
theories are testable in experimental studies and must be confirmed critically in observational studies (Gardner, Lalonde and Pierson, 1983).

\section{Methods}

\section{Participants}

In the current study 124 stuttering students participated with the age range of 15 to 18 years old. These students were studying in the normal schools of Tehran, Iran. In all cases the stuttering problems was created in the childhood period and in order to be sure that all subjects are suffering from stuttering, a speech and language pathologist was asked to examine all the participants. None of the participants used any kind of medicine. Also, in order to be confident about the inexistency of associated deficits such as: Epilepsy, Neurologic problems, Motor control system Deficit, etc, the researchers used the Health Document of each student available in the official documents of their schools. Having examined all the documents, the researcher found that 4 students had associated deficits, i.e. Epilepsy, Neurologic problems, and were using medicines, so 120 students remained as the final group of participants for the study.

\section{Research Questions and Hypothesis}

The present study will address the following research questions:

Q1: Is there any relationship between Cognitive and Metacognitive Strategies of Stuttering Students?

Q2: Is there any relationship between Cognitive strategies and Reading Comprehension of Stuttering Students? 
Q3: Is there any relationship between Metacognitive strategies and Reading Comprehension of Stuttering Students?

To come up with reasonable results on the basis of the aforementioned research questions, the following null hypotheses were proposed:

H01: There is no statistically significant relationship between Cognitive and Metacognitive Strategies of Stuttering Students.

H02: There is no statistically significant relationship between Cognitive strategies and Reading Comprehension of Stuttering Students.

H03: There is no statistically significant relationship between Metacognitive strategies and Reading Comprehension of Stuttering Students.

\section{Measurement Instruments}

There were two sets of measurement instruments in this study: (1) a reading comprehension test; and (2) a cognitive-metacognitive strategy use questionnaire.

Reading comprehension test. The test was organized around a variety of reading tasks with two major parts. There were 80 questions in total: (1) Rational Cloze; and (2) Text Comprehension. The purposes of the two test parts differ in terms of the underlying theoretical reading constructs being measured and in terms of the nature of tasks presented.

Section 1: Fill in the Blanks. This section was designed to measure the readers' ability to comprehend texts using both structural and lexical appropriacy, pragmatics and discourse. The first part of this test section was rational cloze where test takers simply fill in the blanks given in the cloze test, 
whereas the second part was open-ended cloze where test takers needed to produce a suitable word on their own in order to complete the text. A contextually acceptable response scoring method was used for this part.

Section 2: Text Comprehension, assessed through multiple choice questions. This section aimed to measure the readers' ability to comprehend English texts for main ideas, details and inferences. This section was composed of two sections: expeditious reading (i.e., skimming and scanning) and Careful Text Comprehension. The specific reading skills which students needed to demonstrate were: (1) scanning and skimming text for general and specific information; (2) recalling word meanings; (3) evaluating information; (4) guessing meanings of unknown words from context clues; (5) identifying the meaning of key vocabulary items in the text; (6) identifying phrases or word equivalence; (7) predicting topics of passages and the content of a passage; (8) discriminating between more or less important ideas; (9) distinguishing facts from opinions; (10) analyzing reference words in the text; (11) drawing inferences from the content; (12) identifying the title of the text and the appropriate heading; (13) summarizing the content of the given text; (14) recognizing main ideas or purposes of a passage(and distinguish them from supporting ideas); (15) synthesizing information across more than one paragraph in the text; (16) recognizing and recover information in the form of specific details; and (17) recognizing inferences drawn from the statements and information presented in the text. This section consisted of 5 texts ranging from 150 words to 700 words. The texts and words were general/ 
nontechnical in nature to tap into the students' language knowledge as taught in the class. For both major test sections, the topics included family, food and drink, clothing, health, travels, and transportation.

Cognitive and metacognitive strategy questionnaire. Methods typically used to understand the nature of strategies include verbal reports (e.g., think-aloud protocols, retrospective interviews) and self-report questionnaires. In the present study, a likert-scale questionnaire was used. In a context of a large-scale study, it can also be difficult or impossible to taperecord all participants while taking the reading test. Moreover, the thinkaloud methodology is highly complex and the participants need a lot of practice prior to actual data gathering to achieve optimal think-aloud validity. The usefulness of likert-scale questionnaires is supported by many strategy researchers (e.g., O’Malley \& Chamot, 1990; Oxford, 1996; Purpura, 1999) and SEM researchers (e.g., Bentler, 1995; 2006; Byrne, 1994; Kline, 1998). The strategy questionnaire in this study was adopted from the questionnaire used by Phakiti (2003b). Phakiti (2003b) reported the construct validation of the questionnaire. Since Phakiti (2003b) identified some problematic items in his questionnaire, only 30 items that provided a clear structure of cognitive and metacognitive strategies were adopted and re-modified.

\section{Date Collection Procedure}

Pilot study. In this study, the questionnaire was piloted for item-level analysis such as reliability estimates prior to its actual use. The questionnaire was given in Farsi in order to prevent language problems in measuring their 
cognitive and metacognitive strategy use. The questionnaire used in this study allowed learners to mark strategy use on a 5-point Likert scale: 1 (Never), 2 (Sometimes), 3 (Often), 4 (Usually) and 5 (Always). The length of time needed to complete the questionnaire ranged from roughly 10-15 minutes. Having collected the data, their reliability was calculated through SPSS and it turned out to be 0.74 which can be considered as an acceptable reliability index.

Main study. Having done the pilot study, the researchers gave the questioners to the participants and after one week interval the reading comprehension test was administered on the subjects. After the data were imported into SPSS, the covariance matrix was calculated to be used in the LISREL 8.8.

\section{Results and Discussion}

Having imported the data from SPSS software into LISREL and doing all the essential and required analysis, the following model was obtained. 
Figure 1. Relationship between latent and observed variables

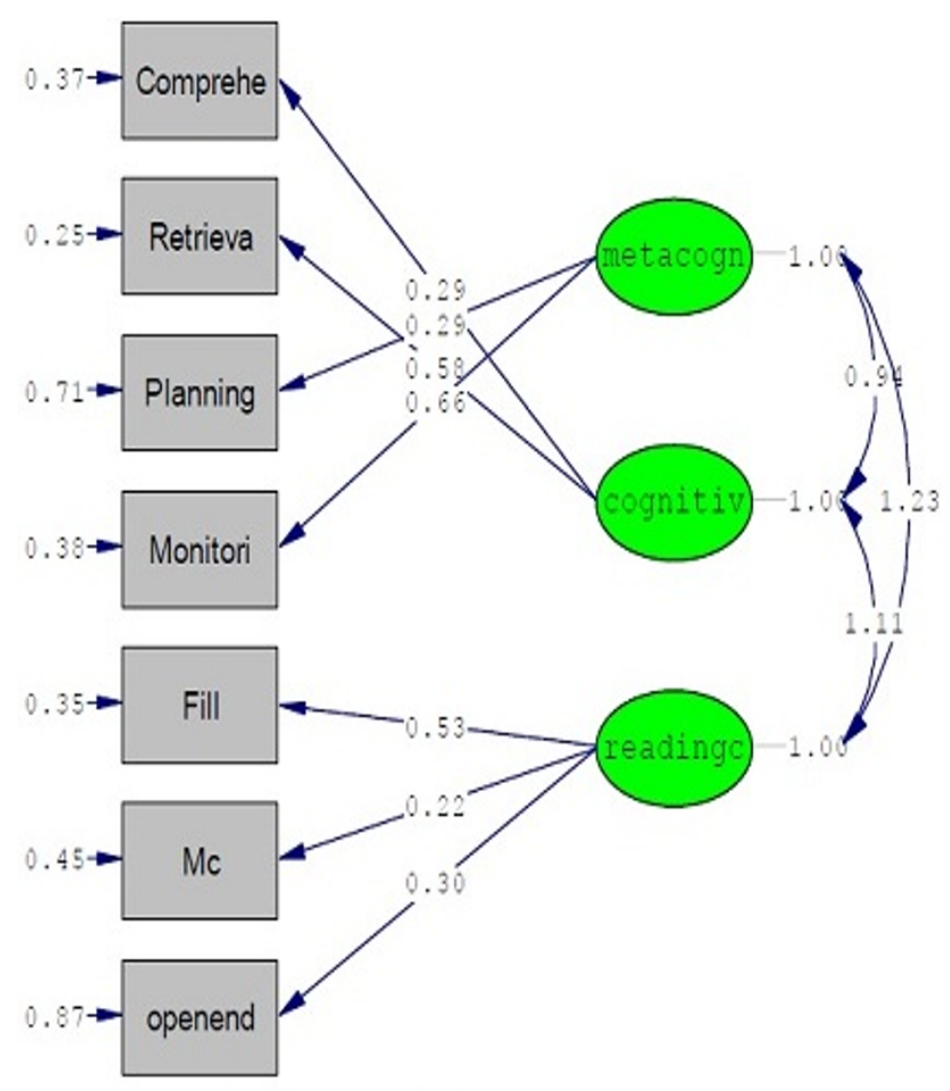

Chi-Square $=18.77, d f=11, \quad$-value $=0.06539$, RMSEA $=0.056$

Since the Chi - Square equals 18.777 and the p-value is larger than 0.06, then we can draw conclusion that the model fits the data, i.e. the model is appropriate. This model only shows the relationship between the latent variables and the observed variables of the study.

The values which are written on each arrow are demonstrated in the Estimated Mood, and they cannot be appropriately interpreted. In all SEM models run in LSREL software, the values of Estimated Mood are not interpretable because there is no principle to which one can compare these values. In order to make the values interpretable, we should change the mood from Estimated Mood to T-Value Mood. Having changed the mood to T-Value, 
we see that all the values written on the arrows of the above model changed and are higher than 1.96 (1.96 is a predetermined principle value to which all the values are to be compared, when the Critical Ratio (CR) is $>1.96$ for a regression weight, that path is significant at the .05 level, i.e. its estimated path parameter is significant) (Ullman, 2001). As a result, we can conclude that there is a meaningful relationship between the observed variables (Retrieval and Comprehension) and their latent variable, i.e. Cognitive Strategies. Also, there is a meaningful relationship between Planning and Monitoring as the Observed variables and Metacognitive Strategies, i.e. latent variables. The relationship between Reading Comprehension as the latent variable and its observed variables, i.e. Fill in the blanks, Multiple Choice and Open-ended items was statistically significant as well.

The first research question aims at investigating the relationship between Cognitive and Metacognitive strategies using SEM.

As figure 2 shows, there was a statistically strong relationship between Cognitive and Metacognitive strategies, i.e. T-Value or Path Coefficient is 2.29 (Figure 2).

Figure 2. Relationship between Cognitive and Metacognitive strategies 


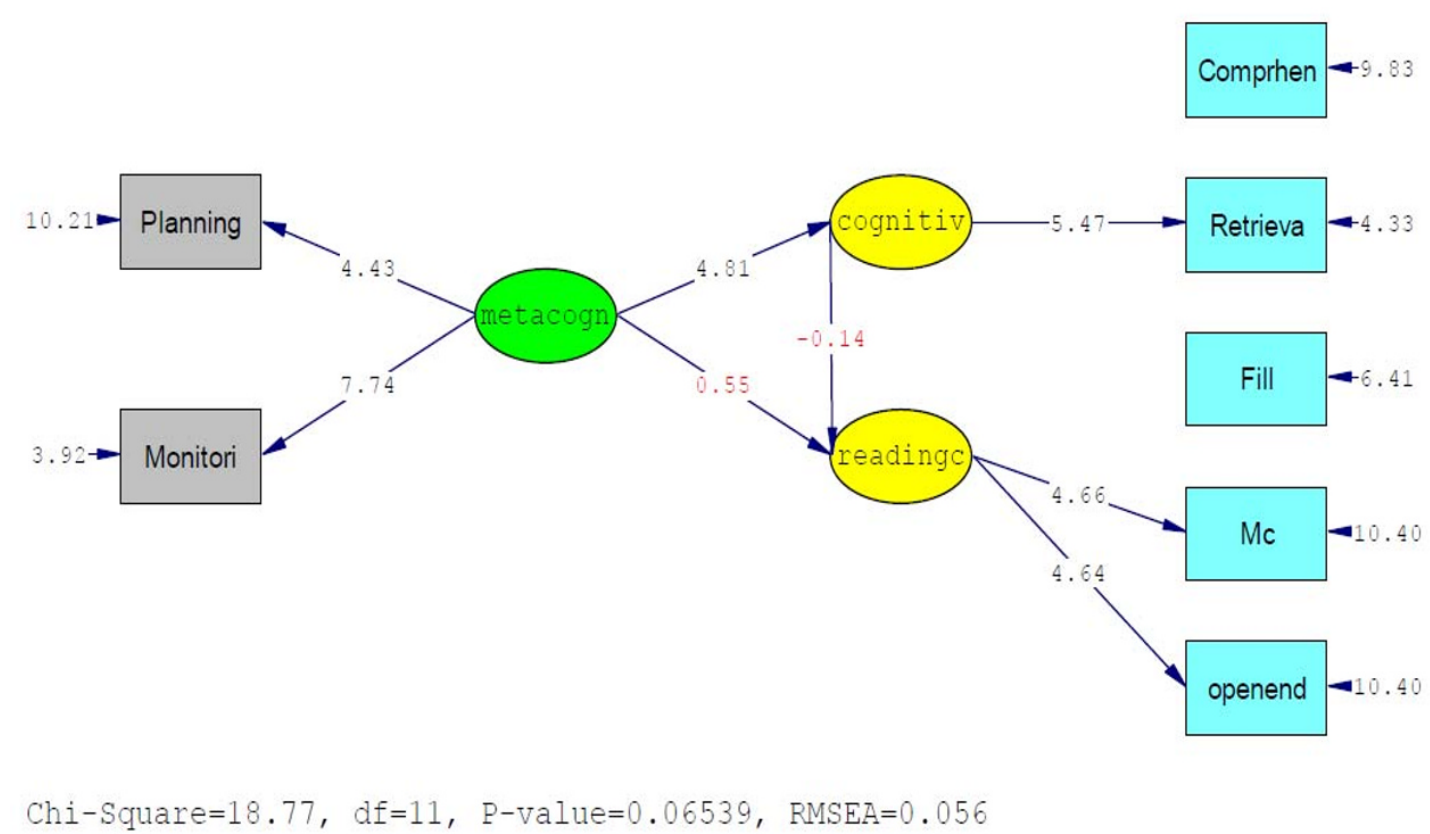

As can be seen in Figure 2, the path coefficient between Cognitive and Metacognitive strategies is reported to be 4.81 . Based on the SEM literature, if the T-value is larger than 1.96 we can conclude that there is a statistically significant relationship between the variables. Consequently, the first null hypothesis developed for the study is rejected, that is, there is a meaningful relationship between Cognitive and Metacognitive strategies of stuttering students.

Considering the second null hypothesis, we can see that T-value between Cognitive Strategies and Reading comprehension is less than 1.96, i.e. - 0.14 , so we can conclude that there is no statistically significant relationship between the Cognitive strategies and Reading Comprehension of Stuttering Students (See Figure 2). The same result can be obtained for the Metacognitive strategies since the T - Value between Metacognitive Strategies and Reading Comprehension is less than 1.96, i.e. 0.55. 
As stated in the literature, SEM allows three significant jobs. Firstly, it estimates the Covariance Matrix. Table 1 below shows the Correlation matrix for the Observed variables of the first study. Second, SEM does the parameter specification including LAMBDA-X, PHI and THETA-DELTA. Parameter specification also calculates the Squared Multiple Correlations for the Variables of the study.

Table 1

Covariance Matrix to be analyzed

\begin{tabular}{lccccccc}
\hline & $\begin{array}{c}\text { Comprehensi } \\
\text { on }\end{array}$ & $\begin{array}{c}\text { Retrieva } \\
1\end{array}$ & $\begin{array}{c}\text { Plannin } \\
\mathrm{g}\end{array}$ & $\begin{array}{c}\text { Monitorin } \\
\mathrm{g}\end{array}$ & $\begin{array}{c}\text { FIB } \\
*\end{array}$ & $\begin{array}{c}\text { MC } \\
*\end{array}$ & $\begin{array}{c}\text { OE } \\
*\end{array}$ \\
\hline Comprehension & .46 & & & & & & \\
\hline Retrieval & .17 & .59 & & & & & \\
\hline Planning & .09 & .13 & .79 & & & & \\
\hline Monitoring & .17 & .37 & .19 & .81 & & & \\
\hline FIB & .18 & .36 & .17 & .42 & .64 & & \\
\hline MC & .07 & .10 & .11 & .21 & .10 & .50 & \\
\hline Op & .10 & .18 & .20 & .24 & .15 & .18 & .96 \\
\hline
\end{tabular}

${ }^{*}$ Note: $F I B=$ Fill in the blanks, $M C=$ Multiple Choice, $O E=$ Open Ended

The next step is to estimate the Goodness of fit Statistics. Goodness of fit tests determines if the model being tested should be accepted or rejected. If the model is accepted, the researcher will continue to read the path coefficients in the model (Ullman, 2001).

Ullman (2001) states that a "good fit" is not the same as strength of relationship. One might have ideal fit when all variables in the model were entirely uncorrelated, provided that the researcher does not instruct the SEM software to constrain the variances. In reality, the lower the correlations predetermined in the model, the easier it is to find "good fit." The stronger the 
correlations, the more power SEM has to identify an incorrect model. When correlations are low, the researcher cannot reject the model at hand (Ullman, 2001).

When the variables have low correlation, the structural (path) coefficients will be low also. Researchers should report not only goodness-offit measures but also should report the structural coefficients so that the strength of paths in the model can be measured. In the case of the first hypothesis, the structural coefficient depicts a strong relationship between the Cognitive and Metacognitive strategies.

Goodness of Fit includes many parameters which are necessary for interpreting the results of the study. For the first step the Degree of freedom should be calculated. Here, for this study, it is estimated to be 8 . Minimum Fit Function Chi-square is 9.35 when p-value is 0.31 . The second parameter is called Estimated non-centrality parameter $(\mathrm{NCP})$ that in this case it is estimated to be 0.47 and 90 percent Confidence interval for NCP is calculated as $0.0 ; 11.78$. The next but the most important factor is Goodness of Fit Index (GFI). Measures of goodness of fit typically summarize the discrepancy between observed values and the values expected under the model in question. In the case of this study, GFI is reported to be 0.92 . Since both Structural coefficient and Goodness of fit are high, we can conclude that not only is the model accepted but also the relationship between Cognitive and Metacognitive strategies of stuttering students.

\section{Conclusion}


A search for applications of SEM in the field of language assessment in the context of Iran will undoubtedly not turn up more than a few papers at most. This low level of interest in SEM among Iranian language testing researchers is probably due to many reasons, the most significant ones are the lack of a pedagogic introduction to SEM for language testing research, very few instances of SEM application to language assessment data, and very little discussion of the virtues and the restrictions of SEM for the field of language assessment.

SEM applications are so extensive today that Marcoulides and Schumacker (1996) utter that

'the use of the term structural equation modeling is broadly defined to accommodate models that include latent variables, measurement errors in both dependent and independent latent constructs, multiple indicators, reciprocal causation, simultaneity and interdependence' (p. 1).

In the 1980s, Gardner and other second language acquisition researchers employed SEM with the data obtained from SLA researches (Gardner, Lalonde and Pierson, 1983; Gardner et al., 1987; Gardner, 1988; Clement and Kruidenier, 1985; Ely, 1986) to scrutinize motivation and attitude as parameters that influence second language acquisition. The most current SEM applications in language assessment include Sasaki (1993), who investigated the relationships among second language proficiency, foreign language aptitude, and intelligence, Kunnan (1995), who explored the influence of some test taker characteristics on test performance in tests of English as a foreign language, Purpura (1996), who examined the 26 I P a g e 
relationships between test takers' cognitive and metacognitive strategy use and second language test performance, and Ginther and Stevens (1998), who investigated the factor structure of an Advanced Placement Spanish language examination among four different Spanish-speaking test taking groups.

Due to the many scientifically - reported advantages of SEM, such as: latent growth modeling, multilevel SEM models, and approaches for dealing with missing data and with violations of normality assumptions, application of SEM in the field of language assessment is highly recommended.

Finally, the current study employed SEM to investigate the relationship between Cognitive and Metacognitive strategies of Stuttering students and their Reading comprehension ability. As discussed thoroughly in the conclusion section, the findings show that there was a statistically significant relationship between cognitive and metacognitive strategies of stuttering students, but no evidence of relationship between cognitive and metacognitive strategies and reading comprehension performance was witnessed.

\section{References}

Anderson, J.C. \& Gerbing, D.W. (1988). Structural equation modeling in practice: A review and recommended two-step approach. Psychological Bulletin, 103, 411-23.

Austin, J.T. \& Caldero'n, R.F. (1996). Theoretical and technical contributions to SEM: An updated bibliography. Structural Equation Modeling, 3, 10575. 
Bentler, P.M. (1986). Structural modeling and Psychometrika: An historical perspective on growth and achievements. Psychometrika, 51, 35-51.

Bentler, P.M. \& Chou, C. P. (1987). Practical issues in SEM. Sociological Methods and Research, 16, 78-117.

Bollen, K.A. (1989). Structural equations with latent variables. New York: Wiley.

Bollen, K.A. \& Long, J.S., editors, (1993): Testing structural equation models. Newbury Park, CA: Sage.

Borkowski, J., Carr, M., \& Pressely, M. (1987). "Spontaneous" strategy use: Perspectives from metacognitive theory. Intelligence, 11, 61-75.

Brown, A. L. (1987). Metacognition, executive control, self-regulation, and other more mysterious mechanisms. In F. E. Weinert \& R. H. Kluwe Eds.), Metacognition, motivation, and understanding (pp. 65-116). Hillsdale, New Jersey: Lawrence Erlbaum Associates.

Carr, M., Kurtz, B. E., Schneider, W., Turner, L. A., \& Borkowski, J. G. (1989). Strategy acquisition and transfer among German and American children: Environmental influences on metacognitive development. Developmental Psychology, 25, 765-771.

Clement, R. \& Kruidenier, B.G. (1985). Aptitude, attitude and motivation in second language proficiency: A test of clement's model. Journal of Language and Social Psychology, 4, 21-37.

Flavell, J. H. (1979). Metacognition and cognitive monitoring: A new area of cognitive-developmental inquiry. American Psychologist, 34, 906-911. 
Flavell, J. H. (1987). Speculations about the nature and development of metacognition. In F. E. Weinert \& R. H. Kluwe (Eds.), Metacognition, Motivation and Understanding (pp. 21-29). Hillside, New Jersey: Lawrence Erlbaum Associates.

Garner, R. (1990). When children and adults do not use learning strategies: Toward a theory of settings. Review of Educational Research, 60, 517-529.

Gardner, R.C., Lalonde, R.N. \& Pierson, R. (1983). The socio-educational model of SLA: An investigation using LISREL causal modeling. Journal of Language and Social Psychology, 2, 1-15.

Gardner, R.C., Lalonde, R.N., Moorcraft, R. \& Evers, F.T. (1987). Second language attrition: The role of motivation and use. Journal of Language and Social Psychology, 6, 1-47.

Gardner, R.C. (1988). The socio-educational model of second language learning: Assumptions, findings and issues. Language Learning, 38, 10126.

Ginther, A. \& Stevens, J. (1998). Language background, ethnicity, and the internal construct validity of the Advanced Placement Spanish language examination. In Kunnan, A.J. (Ed.), Validation in language assessment.

Halpern, D. F. (1996). Thought and knowledge: An introduction to critical thinking. Mahwah, New Jersey: Lawrence Erlbaum Associates, Publishers. 
Livingston, J. A. (1996). Effects of metacognitive instruction on strategy use of college students. Unpublished manuscript, State University of New York, Buffalo.

Kunna, A.J. (1995). Test taker characteristics and test performance: A structural modeling approach. Cambridge: Cambridge University Press.

Marcoulides, G.A. \& Schumacker, R.E. (1996). Advanced SEM: Issues and techniques. Mahwah, NJ: Lawrence Erlbaum Associates, Inc.

National Center for Educational Statistics. (2005). 2009 NAEP reading framework. Washington DC: Institute of Education Sciences, U.S. Department of Education.

National Reading Panel (NRP) (2000). Teaching children to read: An evidencebased assessment of the scientific research literature on reading and its implications for reading instruction: Reports of the subgroups. Bethesda, MD: NICHD.

Nunnally, J. C. (1967). Psychometric Theory. McGraw-Hill: New York.

Pearl, J. (2000). Causality: Models, reasoning, and inference. Cambridge University Press: Cambridge.

Purpura, J.E. (1996). Modeling the relationships between test takers' reported cognitive and metacognitive strategy use and performance on language tests. Unpublished doctoral dissertation, University of California, Los Angeles.

Roberts, M. J. \& Erdos, G. (1993). Strategy selection and metacognition. Educational Psychology, 13, 259-266. 
Sasaki, M. (1993). Relationships among second language proficiency, foreign language aptitude and intelligence: A structural equation modeling approach. Language Learning, 43, 313-44.

Scheid, K. (1993). Helping students become strategic learners: Guidelines for Teaching. Cambridge, MA: Brookline Books.

Simon, H. (1953). Causal ordering and identifiability. In Hood, W.C. \& Koopmans, T. C. (Ed.), Studies in Econometric Method (pp. 49-74). New York: Wiley.

Snow, C. E., Burns, M. S., \& Griffin, P. (1998). Preventing reading difficulties in young children. Washington, DC: National Academy Press.

Sternberg, R. J. (1984). What should intelligence tests test? Implications for a triarchic theory of intelligence for intelligence testing. Educational Researcher, 13(1), 5-15.

Sternberg, R. J. (1986a). Inside intelligence. American Scientist, 74, 137-143.

Sternberg, R. J. (1986b). Intelligence applied. New York: Harcourt Brace Jovanovich, Publishers.

Ullman, J. B. (2001). Structural equation modelling. In Tabachnick, B.G., \& Fidell, L.S. (Ed.), Using multivariate statistics (pp. 653-771). Needham Heights, MA: Allyn \& Bacon.

Van Zile-Tamsen, C. M. (1994). The role of motivation in metacognitive selfRegulation. Unpublished manuscript, State University of New York, Buffalo. 
Van Zile-Tamsen, C. M. (1996). Metacognitive self-regulation and the daily academic activities of college students. Unpublished doctoral dissertation, State University of New York, Buffalo.

Westland, J. C. (2010). Lower bounds on sample size in structural equation modeling. Electron. Comm. Res. Appl, 9(6), 476-487. doi:10.1016/j.elerap.2010.07.003

Wright, Sewall S. (1921). Correlation and causation. Journal of Agricultural Research, 20, 557-85. 